\title{
ANALISIS OF THE ELECTRONIC FUEL INJECTOR OPERATION
}

The paper deals with research results of electronic fuel system injection (FSI) and its possible measurement for diagnostic analysis. In the parts of the paper the design and operation of a typical fuel injection system is described and its electronic part is analysed. The procedure for the detection of the injector malfunction based on the analysis of differential current characteristic has also been proposed. In the end the differences in the electrical parameters of the individual fuel injectors on the based comparison of reference and failure current are shown.

Keywords: electronic fuel injector, diagnostics, measurement, current characteristic analysis

\section{Introduction}

Electronic fuel injector is an important part of the engine gasoline fuel system. The fuel injector is a solenoid valve. Forces which act on the active injector core are caused by friction, spring tension and fuel pressure. Rising current curve is partially different from the curve of an ideal inductor current [1].

The effect which causes a change of permeability is caused by the movement of the needle valve. Injector opening time is visible on the current characteristics and the closing time - on the voltage characteristics. Stopping the movable element of the injector is seen as disturbance on the measured characteristics [2].

\section{Principle of the electronic fuel injector operation}

Electronic fuel injector is an electromagnetic valve. Its internal structure is shown in the Figure 1. The basic part of the valve is armature, needle valve, iron core, electromagnetic coil and returning spring. Before injection, the needle valve is compressed tightly on the fuel needle valve pedestal by spring and fuel. Electromagnetic force provided by injection coil is greater than spring force fuel pressure and friction force. When the current flows through the coil, then the needle valve opens upward, the electronic fuel injector sprays once. When in the injector coil power is turned off, under spring force effect, the needle valve electromagnetic force decreases rapidly. The needle valve starts closing, then an injection process will be finished $[3,4]$.

\section{Measuring system for determining the current and voltage characteristics of the fuel injectors}

Figure 2 shows block diagram of the measuring system for gasoline injectors. The main component of the electronic control device is a programmable controller, which is designed to open and close the transistors. Injectors are connected to the collectors of these transistors. Five buttons keypad allows setting the transistors opening time. LCD display shows the current mode.

To test the operation of the injection system and track the required signals, we have designed a test device to control the injector intake valves of the spark-ignition engine. The control of the electronics is analogous to the signal generator.

The pressure vessel makes it possible to create a liquid pressure (replacing the fuel pump) in the range of 0 to 300 $\mathrm{kPa}$ (Figure 3), which corresponds to the fuel pressure in the automobile. From a pressure vessel, the liquid is brought to a common pipe to which all the injectors are attached.

Vessel flow measuring vessels are placed under individual injectors. They allow to determine differences in the amount of injected fuel by individual injectors and injector flow.

The measured current and voltage characteristics show the deviations from the ideal state. Movement of the core, which

\footnotetext{
* ${ }^{1}$ Milan Sebok, ${ }^{1}$ Miroslav Gutten, ${ }^{2}$ Juraj Adamec, ${ }^{3}$ Adam Glowacz, ${ }^{4}$ Jerzy Roj

${ }^{1}$ Department of Measurements and Applied Electrical Engineering, Faculty of Electrical Engineering, University of Zilina, Slovakia

${ }^{2}$ Department of Mechatronics and Electronics, Faculty of Electrical Engineering, University of Zilina, Slovakia

${ }^{3}$ Computer Science and Biomedical Engineering, Faculty of Electrical Engineering, Automatics, AGH University of Science and Technology,

Krakow, Poland

${ }^{4}$ Faculty of Electrical Engineering, Silesian University of Technology, Gliwice, Poland

E-mail: gutten@fel.uniza.sk
} 


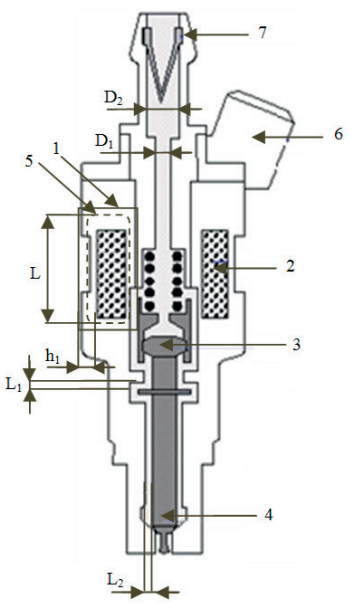

Figure 1 Construction of an electronic fuel injector [5]: 1-iron core, 2-electromagnetic coil, 3-armature, 4-needle valve, 5-yoke of magnet, 6- electrical connection, 7-filter

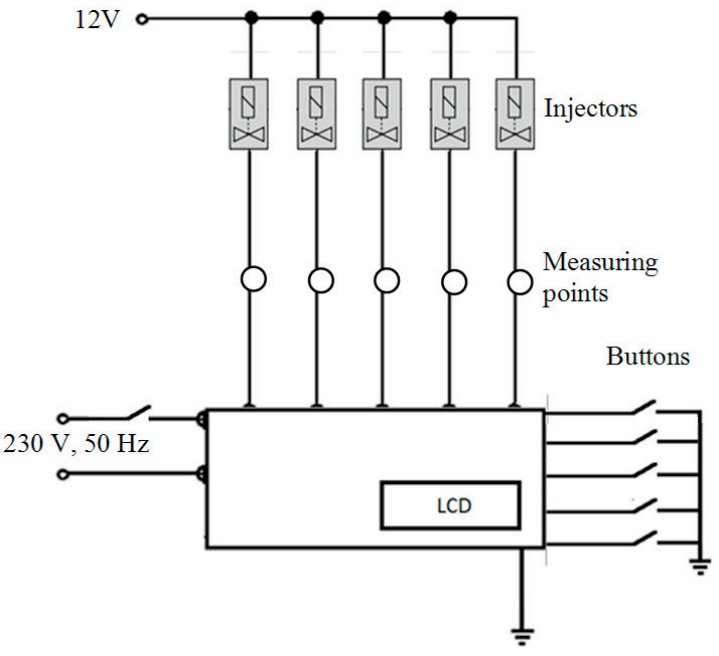

Figure 2 Block diagram of the measuring system

causes the inductance change, affects the current and voltage characteristics.

The measurement results shown in Figure 4 were divided into a few intervals. The interval A is the injector inaction, B refers to moving the injector core, $\mathrm{C}$ is the injection action with the current increasing, D is the injector in operation, $\mathrm{E}$ refers to the overvoltage caused by the inductance of the injector (moving core injector to the initial position), $\mathrm{F}$ is the fading overvoltage and $\mathrm{G}$ is the injector inaction [6].

The time required to open the $12-16 \mathrm{ohm}$ injector is about 1.5 ms. This time is depending on the fuel pressure, injector spring force, inertial core properties, electromagnetic coil, core and injector material. The time required to close the injector is only half of the opening time. Closing of the injector is executed by spring and fuel pressure only.

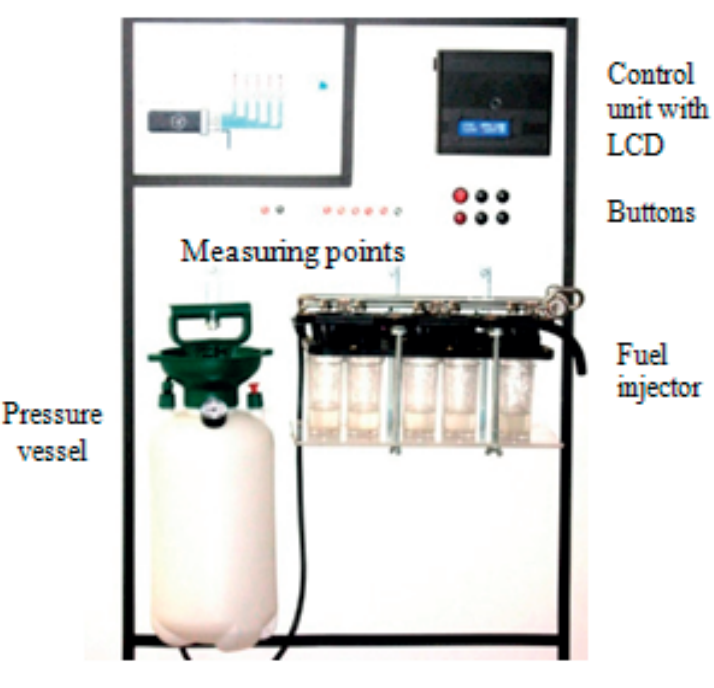

Figure 3 Testing device

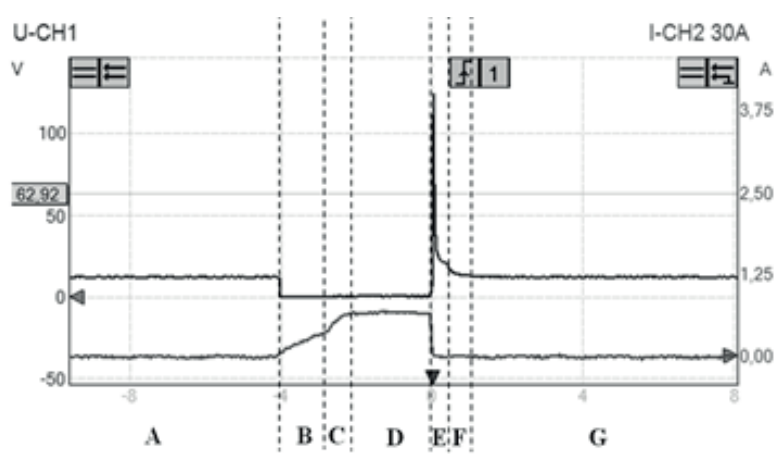

Figure 4 Fuel injector voltage and current characteristics

\section{Current characteristic analysis}

In Figure 5a are shown the measured characteristics of the reference current and failure current. The reference current time behaviour is composed of five measurements with the fluid under pressure at 2.5 bar.

Sampling value on oscilloscope has been set to $100 \mathrm{kS} / \mathrm{s}$ (time between the samples is $10 \mu \mathrm{s})$. The injection time has been set to 5 ms. Characteristic of the failure current was obtained by stopping the needle valve in the open position.

The difference between the reference and fault currents is shown in Figure $5 \mathrm{~b}$. On this characteristic can be seen two extremes. One is in $650 \mu$ s (for current: $64 \mathrm{~mA}$ ) and the second is in $1460 \mu$ s (for current: $-180 \mathrm{~mA}$ ).

Figure 6 shows the current characteristics for another, often occurring movement problem of the injector valve needle. In this case the needle valve solely moves in the top portions of its 
a)

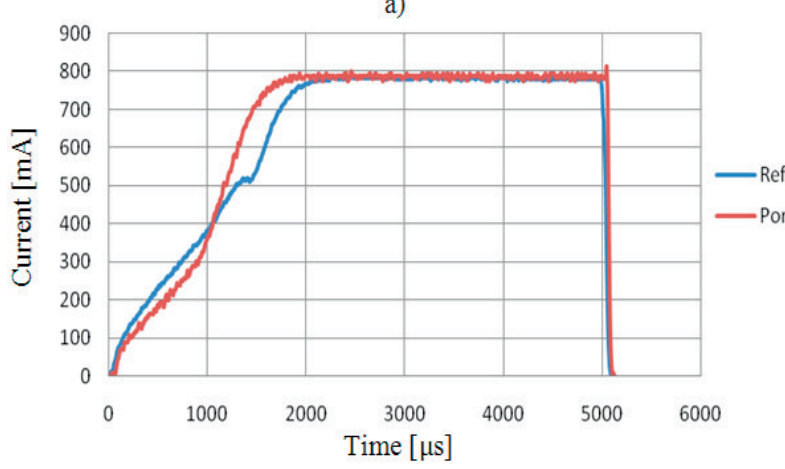

b)

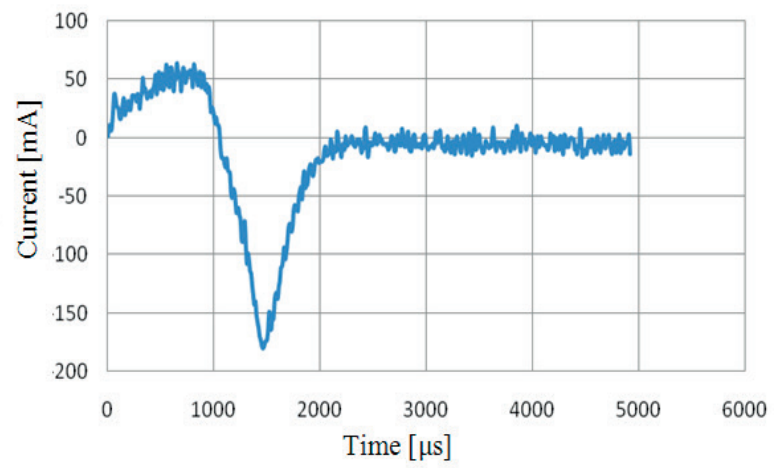

Figure 5 Reference injector current and the current at standstill needle valve in the open position: a) referent and failure currents, b) their difference

a)

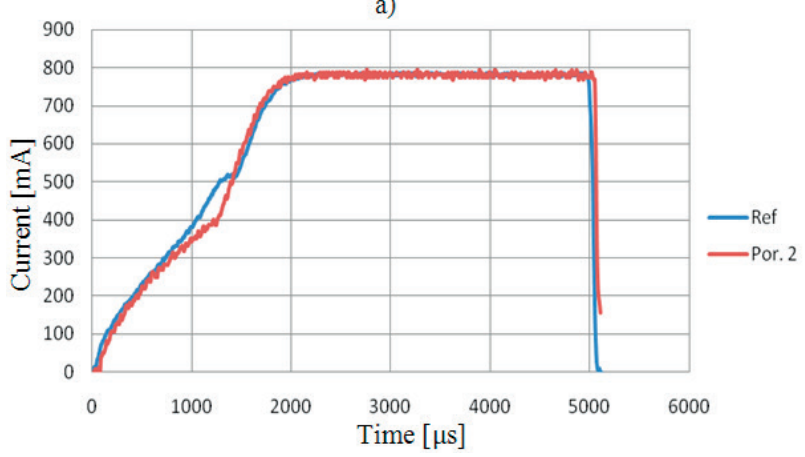

b)

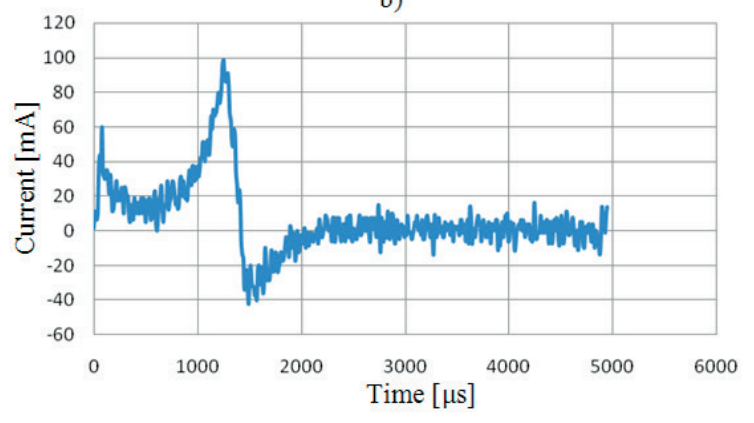

Figure 6 Reference injector current and the partial movement current of the needle valve: a) referent and failure currents, $b$ ) their difference
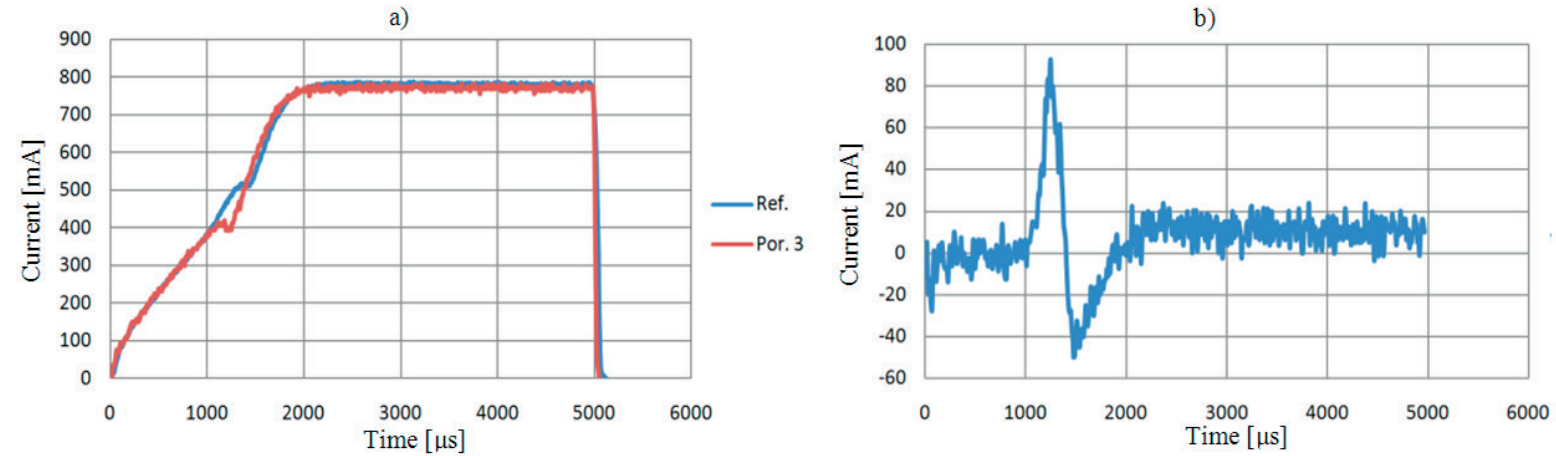

Figure 7 Reference injector current and current at a fuel zero pressure: a) referent and failure currents, $b$ ) their difference

moveable sector. The difference between the reference and failure currents again shows the extremes. The first one is marginal for diagnostics of fuel injector. Two others are in $1250 \mu$ s (for current: $100 \mathrm{~mA})$ and in $1490 \mu \mathrm{s}(-43 \mathrm{~mA})$.

Reduction of the fluid pressure shortens the time necessary to open the fuel injector. This is illustrated by the measurement results shown in Figure 7. On the differential characteristic, again could be seen two extremes, in $1250 \mu$ s (for current: $92.5 \mathrm{~mA}$ ) and in $1480 \mu \mathrm{s}(-50 \mathrm{~mA})$.

There are many types of fuel injectors. The difference is mostly in arrays of injection quantity and in a way of injection (e.g. Figure 8). There are differences by the fuel injector of the same type too. We obtain differences in the characteristics of four fuel injectors from the same car. Measurement results are visible in Figure 9 [7].

\section{Discussion}

In the Figure 10a is visible the influence of the fuel pressure changes on current characteristics. The pressure was increased from 0 to 2.6 bar $(260 \mathrm{kPa})$. 


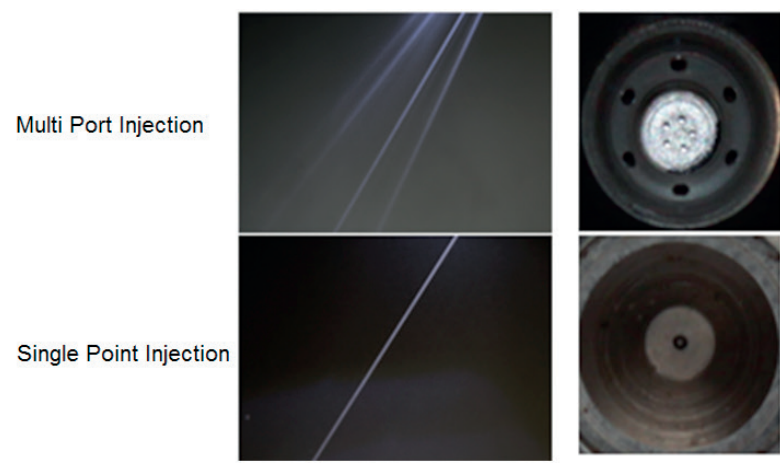

Figure 8 Differences in the injection for different types of injectors

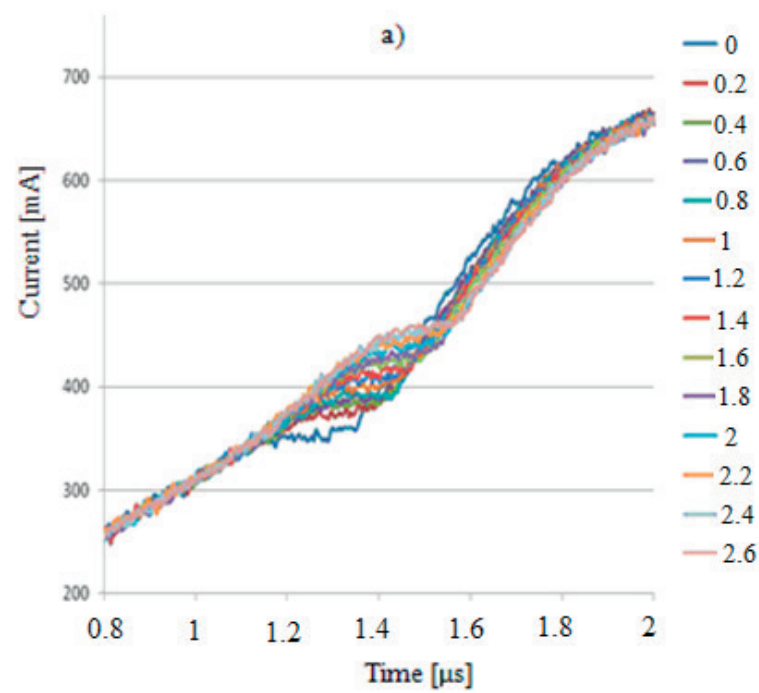

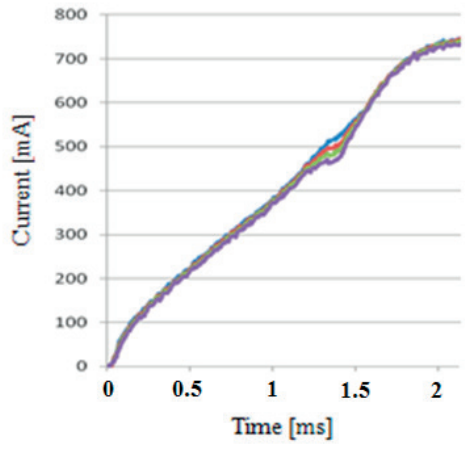

Figure 9 Differences in current characteristics for the same type of the injectors

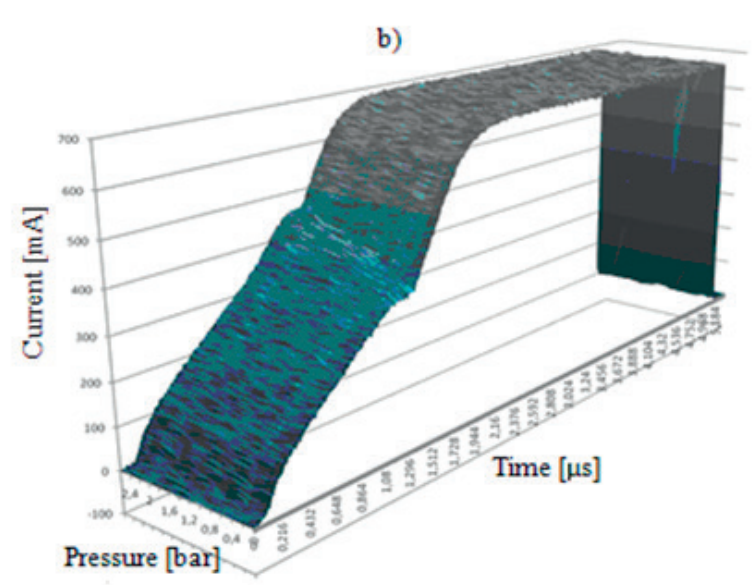

Figure 10 Effect of fuel pressure changes on the current characteristics: a) $2 d$ chart, b) $3 d$ chart

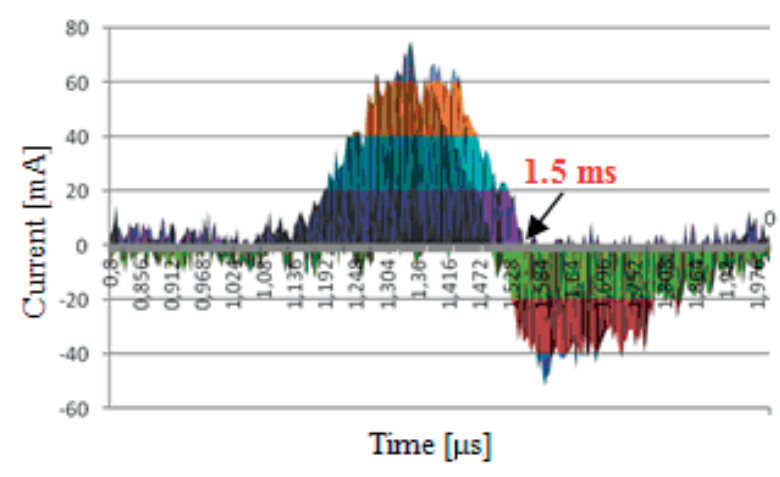

Figure 11 Current waveform during the fuel pressure drop
Subtracting the reference signal from the chart shown in Figure $10 \mathrm{~b}$ allows obtaining a differential signal, which may be treated as a fault signal or a fault decomposition.

The exemplary fault decomposition is illustrated in Figure 11 As the cause of failure is assumed the fuel pressure drop caused

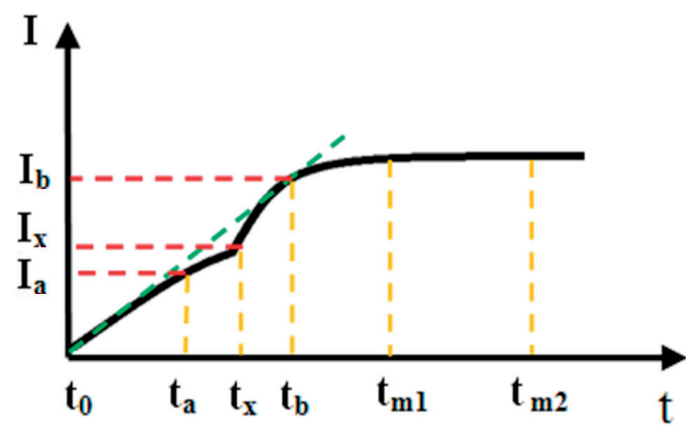

Figure 12 Current characteristic with marked moments of time in which the current measurement allows to determine the state of the injector system

by, for example, inactive hot pump, choked fuel filters, damaged tubes and eventually corrupted regulator pressure. The time to open the fuel injector is approximately $1.5 \mathrm{~ms}$. 


\section{kanNllkacle}

\section{Conclusion}

Figure 12 shows the idealized timing chart of the current during the fuel injector operation. Some characteristic moments of time and the corresponding current values have been marked on it which can be useful for determining the state of the injection system. It is possible to determine the opening time of the fuel injector by monitoring the $t_{\mathrm{x}}$ time. This time had influence on the pressure ratios of fuel jet and assembled the solution of the injector. It is possible to determine the fault fuel pressure by evaluating these times or determining the damage of reversible springs of the fuel injector. Implementing measurement in the times $t_{\mathrm{m} 1}$ and $t_{\mathrm{m} 2}$, allows to obtain the maximum current.
The fuel injectors have many differences resulting from the production technology. It causes difference in the injector voltage and current characteristic. In order to detect the fault state, it is needed to use self-learning process, by the use of an appropriate self-learning algorithm. Such issues will be described in the next paper.

\section{Acknowledgments}

This work was supported by the Grant Agency VEGA from the Ministry of Education of Slovak Republic under contract $1 / 0602 / 17$.

\section{References}

[1] TRAISTARU A., SORA, I.: Real Time Estimation of Li-Ion Battery Resistance Used in the Automotive Industry. Journal of Electrical Engineering, 10(4), 10-15, 2010.

[2] LONGFA X., ZHENDONG Z., Hui G., etc: Research on the Opening and Closing Times of an Electromagnetic Injector. Journal of University of Shanghai for Science and Technology. 32, 297-301, 2010.

[3] ZHONGYI M., YAOYI Q., XIUMIN Y., etc.: Mathematical Model for the Injection Process of the Electronic Controlled Injectors. Transactions of CSICE, 15(2), 231-236, 1997.

[4] CONGBO Y., ZHENDONG Z., ZHIYUAN L.: Experimental Research and Design for Electronic Control Injector Test about Flow Characteristic. Journal of Agricultural Mechanization Research, 12, 194-196, 2007.

[5] CHEN L., ZHANG Z.: Study on the Measurement of Dynamic Characteristics for Automotive Electronic Fuel Injector. International Conference on Transportation, Mechanical, and Electrical Engineering (TMEE 2011), China, 511-514, 2011.

[6] SIMKO M., CHUPAC, M.: Non-Destructive Method of Measurement of Radio Transmitters Antenna Systems. Elektronika ir Elektrotechnika/Electronics and Electrical Engineering, 107(1), 33-36, 2011.

[7] DELLI COLLI, V., MARINETTI, F.: Traction Control for a PM Axial-Flux In-Wheel Motor. Journal of Electrical Engineering, 7(4), 2007. 